\title{
HUBUNGAN PENGGUNA KB IMPLANT DENGAN BERAT BADAN DAN SIKLUS HAID AKSEPTOR KB DI PMB ERLINA PALEMBANG TAHUN 2021
}

\author{
Rama Agustina \\ STIK Bina Husada Palembang, Palembang, Indonesia \\ Email: agustinarama80@gmail.com
}

\begin{abstract}
Abstrak
Latar Belakang : Kontrasepsi adalah upaya untuk mencegah terjadinya kehamilan. Implant adalah salah satu jenis kontrasepsi yang berupa susuk yang terbuat dari sejenis karet silastik yang berisi hormon, dipasang pada lengan atas. Implant dapat digunakan untuk jangka panjang 5 tahun dan bersifat seversible. Berat badan adalah parameter antropometri yang sangat labil. Siklus menstruasi adalah proses perubahan hormon yang terus-menerus dan mengarah pada pembentukan endometrium, ovulasi, serta peluruhan dinding jika kehamilan tidak terjadi.

Tujuan Penelitian : Untuk mengetahui hubungan penggunaan KB Implant dengan berat badan dan siklus haid akseptor KB di PMB Erlina

Metode : dengan pendekatan cross sectional study. penelitian ini semua akseptor KB Implant di PMB Erlina berjumlah 32 orang. Teknik sampling menggunakan Total Sampling Analisis data Univariat dan Bivariat.

Hasil : analisis data diperoleh nilai $p$ value 0,072 < 0,05 maka dapat disimpulkan bahwa Ha ditolak dan Ho diterima, sehingga tidak ada hubungan antara penggunaan kb implant dengan berat badan di PMB Erlina. analisis data diperoleh nilai $p$ value 0,039>0,05 maka dapat disimpulkan bahwa Ha diterima dan Ho ditolak, sehingga ada hubungan antara penggunaan kb implant dengan perubahan siklus haid di PMB Erlina. Diharapkan bagi penguna KB Implant untuk
\end{abstract}

Kata Kunci : Berat Badan, Siklus Haid, KB Implant

\section{Abstract}

Background: Contraception is an effort to prevent pregnancy. Implant is a type of contraception in the form of an implant made of a kind of silastic rubber containing hormones, which is attached to the upper arm. Implants can be used for a long term of 5 years and are seversible. Body weight is a very unstable anthropometric parameter. The menstrual cycle is a continuous process of hormonal changes that lead to the formation of the endometrium, ovulation, and shedding of the walls if pregnancy does not occur.

Research Objectives : To determine the relationship between the use of KB Implants with body weight and menstrual cycle of KB acceptors at PMB Erlina Method : with a cross sectional study approach. In this study, all KB Implant acceptors at PMB Erlina were 32 people.

Sampling technique using Total Sampling Univariate and Bivariate data analysis. Results :data analysis obtained $p$ value $0.072<0.05$, it can be concluded that Ha is rejected and Ho is accepted, so there is no relationship between the use of KB implants and body weight at PMB Erlina. Data analysis obtained p value 0.039>0.05, it can be concluded that Ha is accepted and Ho is rejected, so there is a relationship between the use of birth control implants and changes in the menstrual cycle at PMB Erlina. It is hoped that KB Implant users will:

Keywords: Body Weight, Menstrual Cycle, KB Implant 


\section{JURNAL ILMIAH KEBIDANAN \\ E-ISSN 2774-4671}

\section{Pendahuluan}

Kontrasepsi adalah upaya untuk mencegah terjadinya kehamilan. Upaya itu dapat bersifat sementara, dapat pula bersifat permanen. Penggunaan kontrasepsi merupakan salah satu variabel yang mempengaruhi fertilitas (Wikjosastro, 2012). Kontrasepsi dapat diartikan tindakan yang membantu pasangan suami istri untuk menghindari kehamilan yang tidak diinginkan, mendapatkan kelahiran yang sangat diinginkan, mengatur interval diantara kehamilan, mengontrol waktu saat kehamilan dan berhubungan dengan umur suami istri serta menentukan jumlah anak dalam keluarga (Suratun, 2014).

Salah satu kontrasepsi jangka panjang (MKJP) adalah implant. Implant adalah metode kontrasepsi yang hanya mengandung progestin dengan masa kerja panjang, dosis rendah, reversible untuk wanita (Speroff leon ,2015).

Implant adalah salah satu jenis kontrasepsi yang berupa susuk yang terbuat dari sejenis karet silastik yang berisi hormon, dipasang pada lengan atas. Implant dapat digunakan untuk jangka panjang 5 tahun dan bersifat seversible. Keuntungan dari kontrasepsi yang efektifitasnya tinggi, angka kegagalan implant, 1 per 100 wanita pertahun dalam 5 tahun pertama, kegagalan pengguna rendah, sekali terpasang tidak perlu ada yang diingat. Implant berisi levonorgestrel yang merupakan hormon progesteron (Endang Purwoastuti, 2015)

Efek samping Implant paling utama adalah perubahan pola haid, yang terjadi pada kira-kira $60 \%$ akseptor dalam tahun pertama setelah insersi. Yang paling sering terjadi adalah bertambahnya hari-hari perdarahan dalam siklus, perdarahan-bercak (spotting), berkurangnya panjang siklus haid, amenore meskipun lebih jarang terjadi dibandingkan perdarahan lama atau perdarahan bercak (Endang Purwoastuti, 2015).

Berdasarkan Data yang diperoleh dari PMB Erlina, pada tahun 20219 jumlah peserta KB aktif sebanyak 580 peserta, dan akseptor yang menggunakan metode suntikan sebanyak $352(0.61 \%)$ peserta, pil sebanyak 169 $(0,29 \%)$ peserta, implant sebanyak $43(2,7 \%)$ peserta, IUD sebanyak $3(0,19 \%)$ peserta, dan penggunaan kondom sebanyak $13(0,07 \%)$ peserta. Sedangkan data pada tahun 2020 jumlah KB aktif sebanyak 631 peserta, yang menggunakan metode suntikan $397(0,63 \%)$ peserta, pil sebanyak $176(0,28 \%)$ peserta, implant sebanyak $45(0,07 \%)$ peserta, IUD sebanyak $1(0,16 \%)$ peserta, dan Pengunaan kondom sebanyak 12 $(0,02 \%)$ peserta. (Data PMB Erlina,2020).

\section{Metode Penelitian}

Desain dalam penelitian ini yang digunakan yaitu survey analitik dengan pendekatan cross sectional study.

Defenisi Operasional

\begin{tabular}{|c|c|c|c|c|c|}
\hline No. & Variabel & Defenisi & Alat Ukur & Kriteria & Skala Ukur \\
\hline 1 & $\begin{array}{l}\text { Variabel } \\
\text { Independen: } \\
\text { Berat Badan }\end{array}$ & $\begin{array}{l}\text { parameter antropometri yang } \\
\text { sangat labil }\end{array}$ & Kuisioner & $\begin{array}{l}\text { 1.Naik } \\
\text { 2.Tidak Naik }\end{array}$ & Ordinal \\
\hline 2 & Siklus Haid & $\begin{array}{l}\text { proses perubahan hormon yang } \\
\text { terus-menerus dan mengarah pada } \\
\text { pembentukan endometrium, } \\
\text { ovulasi, serta peluruhan dinding } \\
\text { jika kehamilan tidak terjadi. }\end{array}$ & Kuisioner & $\begin{array}{l}\text { 1.Ya } \\
\text { 2.Tidak }\end{array}$ & Ordinal \\
\hline 3 & KB implant & $\begin{array}{l}\text { metode kontrasepsi hormonal yang } \\
\text { efektif, tidak permanen dan dapat } \\
\text { mencegah terjadinya kehamilan } \\
\text { antara tiga sampai lima tahun }\end{array}$ & Kuisioner & $\begin{array}{l}\text { 1.Ya } \\
\text { 2.Tidak }\end{array}$ & Ordinal \\
\hline
\end{tabular}




\section{JURNAL ILMIAH KEBIDANAN}

E-ISSN $2774-4671$

Populasi dan Sampel

a. Populasi

Populasi dalam penelitian ini semua akseptor KB Implant di PMB Erlina berjumlah 32 orang.

b. Sampel

Sampel pada penelitian ini adalah Total Sampling seluruh populasi dalam penelitian ini yaitu 32 orang.

Teknik pengumpulan data

Dalam penelitian ini data yang digunakan adalah data primer

Analisis data (Univariat dan Bivariat)

Tujuan Penelitian

Tujuan Umum

Diketahuinya Hubungan Penggunaan KB Implant dengan Berat Badan dan Siklus Haid Akseptor KB di PMB Erlina

Tujuan Khusus

a. Diketahuinya distribusi frekuensi Berat Badan pada akseptore KB di PMB Erlina

b. Diketahuinya distribusi frekuensi Perubahan Siklus Haid di PMB Erlina

Duketahuinya Hubungan Penggunaan KB Implant dengan Berat Badan dan Siklus Haid Akseptor KB di

PMB Erlina

\section{Hasil Dan Pembahasan \\ Hasil}

Berdasarkan hasil pengumpulan data primer dan sekunder mengenai Hubungan Penggunaan KB Implant dengan Berat Badan dan Siklus Haid Akseptor KB di PMB Erlina.

Analisa Univariat

Tabel.4.1

Distribusi frekuensi Berat Badan

Berat Badan

\begin{tabular}{|l|r|r|r|r|}
\hline & Frequency & Percent & Valid Percent & $\begin{array}{c}\text { Cumulative } \\
\text { Percent }\end{array}$ \\
\hline Valid Naik & 22 & 68.8 & 68.8 & 68.8 \\
& Tidak Naik & 31.3 & 31.3 & 100.0 \\
Total & 32 & 100.0 & 100.0 & \\
\hline
\end{tabular}

Berdasarkan table diatas diketahui terdiri dari 32 responden yang memiliki berat badan naik sebanyak 22 orang $(68,8 \%)$ dan yang memiliki berat badan yang tidak naik sebanyak 10 orang $(31,3 \%)$ 


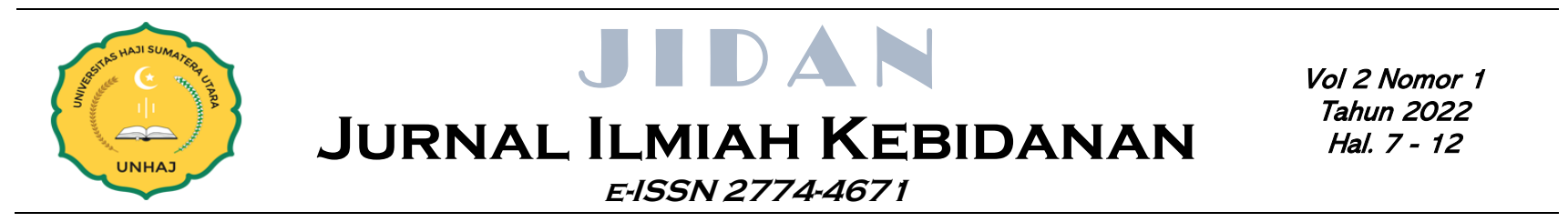

Tabel 4.2.

Distribusi frekuensi Siklus Haid

Siklus Haid

\begin{tabular}{|r|r|r|r|r|}
\hline & Frequency & Percent & Valid Percent & \multicolumn{2}{c|}{$\begin{array}{c}\text { Pumulative } \\
\text { Percent }\end{array}$} \\
\hline Valid Ya & 28 & 87.5 & 87.5 & 87.5 \\
& 4 & 12.5 & 12.5 & 100.0 \\
Tidak & 32 & 100.0 & 100.0 & \\
Total & & & \\
\hline
\end{tabular}

Berdasarkan table diatas diketahui bahwa dari 32 responden yang memiliki perubahan siklus haid ya sebanyak 28 orang $(87,5 \%)$ dan yang memiliki perubahan siklus haid yan tidak sebanyak 4 orang $(12,5 \%)$

Tabel 4.3.

Distribusi frekuensi pengguna kb implant

Kb Implant

\begin{tabular}{|c|c|c|c|c|c|}
\hline & & Frequency & Percent & Valid Percent & $\begin{array}{c}\text { Cumulative } \\
\text { Percent }\end{array}$ \\
\hline \multirow[t]{3}{*}{ Valid } & $\mathrm{Ya}$ & 24 & 75.0 & 75.0 & 75.0 \\
\hline & Tidak & 8 & 25.0 & 25.0 & 100.0 \\
\hline & Total & 32 & 100.0 & 100.0 & \\
\hline
\end{tabular}

Tabel. 4.4.

Hubungan Pengguna KB implant dengan berat badan

\begin{tabular}{|l|l|l|l|l|l|l|l|}
\hline \multirow{2}{*}{ Kb implant } & \multicolumn{3}{|l|}{ Berat badan } & \multicolumn{2}{l|}{ Total } & \multirow{2}{*}{ P value } \\
\cline { 2 - 7 } & Naik & $\%$ & $\begin{array}{l}\text { Tidak } \\
\text { Naik }\end{array}$ & $\%$ & F & $\%$ & \\
\cline { 1 - 6 } Ya & 19 & 79,2 & 5 & 20,8 & 24 & 100 & \\
\hline Tidak & 3 & 37,5 & 5 & 62,5 & 8 & 100 & \multirow{2}{*}{0,072} \\
\hline Total & 22 & 68,8 & 10 & 31,3 & 32 & 100 & \\
\hline
\end{tabular}

Berdasarkan table diatas diketahui bahwa dari 32 responden penggunaan kb implant sebanyak 24 orang dengan berat badan naik sebanyak 19 orang $(79,2 \%)$ dan dengan berat badan tidak naik sebanyak 5 orang $(20,8 \%)$. Sedangkan yang tidak menggunakan kb implant sebanyak 8 orang yang dengan berat badan naik sebanyak 3 orang $(37,5 \%)$ dan yang dengan berat badan tidak naik sebanyak 5 orang $(62,5 \%)$. 


\section{JURNAL ILMIAH KEBIDANAN \\ E-ISSN 2774-4671}

Dari hasil perhitungan menggunakan uji Chi-Square diperoleh $p$ value $0,072<0,05$ maka dapat disimpulkan bahwa Ha ditolak dan Ho diterima, sehingga tidak ada hubungan antara penggunaan $\mathrm{kb}$ implant dengan berat badan di PMB Erlina

Tabel 4.4.

Hubungan Pengguna KB implant dengan siklus haid

\begin{tabular}{|c|c|c|c|c|c|c|c|}
\hline \multirow[t]{2}{*}{ Kb Implant } & \multicolumn{4}{|c|}{ Siklus Haid } & \multicolumn{2}{|c|}{ Total } & \multirow[t]{2}{*}{$P$ value } \\
\hline & $\mathrm{Ya}$ & $\%$ & Tidak & $\%$ & $\mathrm{~F}$ & $\%$ & \\
\hline $\mathrm{Ya}$ & 23 & 95,8 & 1 & 4,2 & 24 & 100 & \multirow{3}{*}{0,039} \\
\hline Tidak & 5 & 62,5 & 3 & 37,5 & 8 & 100 & \\
\hline Total & 28 & 87,5 & 4 & $12,, 5$ & 32 & 100 & \\
\hline
\end{tabular}

Berdasarkan table diatas diketahui bahwa dari 32 responden penggunaan kb implant sebanyak 24 orang yang mengalami perubahan siklus haid sebanyak 23 orang $(95,8 \%)$ dan tidak mengalamiperubahan siklus haid sebanyak 1 orang $(4,2 \%)$. Sedangkan yang tidak menggunakan kb implant sebanyak 8 orang yang mengalami perubahan siklus haid sebanyak 5 orang $(62,5 \%)$ dan yang tidak perubahan siklus haid sebanyak 3 orang $(37,5 \%)$.

\section{Pembahasan}

\section{Hubungan Penggunaan KB Implant dengan Berat Badan dan Siklus Haid Akseptor KB di PMB Erlina}

Berdasarkan hasil yang peneliti lakukan sejalan dengan teori bahwa Berat badan naik atau turun, maka berikan informasi pada klien bahwa perubahan berat badan 1-2 $\mathrm{kg}$ adalah normal. Kaji ulang jika terjadi perubahan berat badan $2 \mathrm{~kg}$ atau lebih namun apabila perubahan tidak dapat diterima maka bantu klien untuk mencari kontrasepsi lain (BKKBN, 2014).

Berdasarkan hasil peneliti lakukan tidak sejalan dengan penelitian Hasliana Haslan dan Indryani dengan judul Hubungan Penggunaan KB Implant dengan Berat Badan bahwa Hasil penelitian menunjukkan bahwa ada hubungan antara penggunaan implan dengan berat badan akseptor dengan hasil uji chi square diperoleh nilai $\mathrm{p}=0,015$.

Dari hasil perhitungan menggunakan uji Chi-Square diperoleh $p$ value 0,039 > 0,05 maka dapat disimpulkan bahwa Ha diterima dan Ho ditolak, sehingga ada hubungan antara penggunaan kb implant dengan perubahan siklus haid di PMB Erlina

Berdasarkan hasil peneliti lakukan sejalan dengan teori Menurut Saifuddin (2010) beberapa klien dapat mengalami perupahan pola haid berupa pendarahan bercak (spotting), hipermenorhea, atau meningkatkan darah haid serta amenorhea.

Berdasarkan hasil peneliti lakukan sejalan dengan penelitian Hasliana Haslan dan Indryani dengan judul Hubungan Penggunaan KB Implant dengan Siklus Haid bahwa Hasil penelitian menunjukkan bahwa ada hubungan antara penggunaan implan dengan hasil uji chi square diperoleh nilai $p=0,001$ 


\section{JURNAL ILMIAH KEBIDANAN \\ E-ISSN 2774-4671}

\section{Kesimpulan}

Berdasarkan hasil penelitian yang diperoleh telah diketahuinya distribusi frekuensi Berat Badan pada akseptore KB naik di PMB Erlina sebanyak 22 orang $(68,8 \%)$ dan yang memiliki berat badan yang tidak naik sebanyak 10 orang $(31,3 \%)$. Telah diketahuinya distribusi frekuensi Perubahan Siklus Haid di PMB Erlina yang memiliki perubahan siklus haid ya sebanyak 28 orang $(87,5 \%)$ dan yang memiliki perubahan siklus haid yan tidak sebanyak 4 orang (12,5\%). Telah diketahuinya tidak ada hubungan Penggunaan KB Implant dengan Berat Badan dan ada hubungan penggunaan kb implant dengan Siklus Haid Akseptor KB di PMB Erlina

\section{Referensi}

Endang Purwoastuti. 2015. Panduan Materi Kesehatan Reproduksi \& Keluarga Berencana. Jakarta. Pustaka Baru.

Gibson, 2015. Principles of Nutritional Assessment. Second Edition. Oxford University Press Inc, New York.

Hanafiah, 2009. Haid dan Siklusnya. In: Wiknjosastro, H. ed. Ilmu Kandungan Edisi Kedua Cetakan Ketujuh. Jakarta: PT Bina Pustaka Sarwono Prawihardjo

Hartanto. 2004, Keluarga Berencana dan Kontrasepsi. Jakarta: Pustaka Sinar Harapan

Hartriyanti dan Triyanti, 2013. Penilaian Status Gizi, dalam Gizi dan Kesehatan Masyarakat.

PT Raja Grafindo Persada, Jakarta.

Hidayat, 2010. Pengantar Ilmu Keperawatan Anak jilid I, Jakarta : Salemba Medika.

Jones. 2012. Dasar-dasar Obstetri dan Ginekologi. Jakarta: Hipokrates

Meilani, Niken. (2010). Pelayanan Keluarga Berencana Fitrayama : Yogyakarta

Sarwono, 2012. Ilmu Kebidanan. Jakarta: PT Bina Pustaka Sawono

Setiawan, 2010. Metodelogi Penelitian Kebidanan. Yogyakarta: Nuha Medika.

Suratun, 2014. Pelayanan Keluarga Berencana dan Pelatanan Kontrasepsi. Yogyakarta:

Trans Info Media.

Wikjosastro, 2012. Buku panduan Praktis Pelayanan Kesehatan Maternal dan Neonatal,

Edisi 1. Cet. 12. Jakarta: Bina Pustaka 